\title{
Self-propagating waves of crystallization in metallic glasses
}

\author{
A.S.Rogachev ${ }^{1,2 *}$, S.G.Vadchenko ${ }^{1}$, A.S.Aronin ${ }^{3}$, S.Rouvimov $^{4}$, A.A.Nepapushev ${ }^{2}$, \\ I.D.Kovalev ${ }^{1}$, F.Baras ${ }^{5}$, O.Politano ${ }^{5}$, S.A.Rogachev ${ }^{1} \&$ A.S.Mukasyan ${ }^{4}$
}

${ }^{1}$ Institute of Structural Macrokinetics and Materials Science Russian Academy of Sciences (ISMAN), Chernogolovka 142432, Russia

${ }^{2}$ National University of Science and Technology MISiS, Moscow 119049, Russia

${ }^{3}$ Institute of Solid State Physics Russian Academy of Sciences, Chernogolovka 142432, Russia

${ }^{4}$ University of Notre Dame, Notre Dame, Indiana 46556, United States

${ }^{5}$ Laboratoire Interdisciplinaire Carnot de Bourgogne, UMR 6303 CNRS - Université Bourgogne Franche Comté, Dijon 21000, France

\begin{abstract}
Self-propagating thermal waves of the amorphous-crystalline transformation in Fe-based metallic glasses, obtained by melt spinning, were observed using a high-speed infrared camera and reported here. Some experimental results are also reported concerning oscillating waves in the CuTi glassy foils. The thermal characteristics and wave propagating velocities, as well as the microstructure and atomic structure transformations were studied. A comparison of the results with exothermic reaction waves and explosive crystallization shows that the self-propagating waves in metallic glasses are slower and less violent than classical explosive crystallization in deposited films; thus we suggest naming this phenomenon "soft explosive crystallization". The experimental data was confirmed by molecular dynamics simulation of the crystallization phenomenon.
\end{abstract}


Metastable amorphous materials can be produced by several routes, including electrolytic or vacuum deposition ${ }^{1,2}$, melt quenching ${ }^{3,4}$ and mechanical amorphization ${ }^{5,6}$. Amorphous phases, obtained by rapid cooling of metallic melts, called metallic glasses (MG), possess unique magnetic, mechanical, corrosion resistive, and other properties ${ }^{7-9}$. Fe-based amorphous alloys, such as $\mathrm{Fe}-\mathrm{B}, \mathrm{Fe}-\mathrm{Si}-\mathrm{B}$ doped with $\mathrm{Cu}, \mathrm{Nb}$, etc., are widely used as soft magnetic materials (e.g., Metglas $\left.{ }^{\circledR}\right)^{10,11}$. The $\mathrm{Cu}-\mathrm{Ti}, \mathrm{Cu}-\mathrm{Zr}$, or $\mathrm{Cu}-\mathrm{Nb}$ based materials show outstanding mechanical properties $^{12,13}$ and also are used as model systems for fundamental studies of atomic structure and ordering in $\mathrm{MG}^{14-16}$. A combination of several alloying elements resulted in a decrease of the critical quenching rate required to obtain $\mathrm{MG}$ from $10^{6} \mathrm{~K} \mathrm{~s}^{-1}$ to $1 \mathrm{~K} \mathrm{~s}^{-1}$, which permits production of bulk MGs for a variety of engineering applications ${ }^{9,17,18}$. On the other hand, recently, ultrafast quenching at $10^{14} \mathrm{~K} \mathrm{~s}^{-1}$ has allowed for the production of pure glassy metal (tantalum) ${ }^{19}$. Thus, metallic glasses have formed a new, rapidly expanding niche in materials science and technologies, and already involve a large number of metals and alloys.

Some deposited amorphous metal or semiconductor films exhibit peculiar phenomena named "explosive crystallization", i.e. rapid self-propagation of the amorphous-crystalline transformation in the form of a thermal wave $\mathrm{e}^{1,20-24}$. However, this phenomenon has not been observed in metallic glasses produced by melt quenching. Though explosive crystallization was posited as a possible crystallization mechanism in Fe-Zr metallic glasses ${ }^{25}$, no evidence of selfpropagating waves was reported. Recently, we have found self-propagating waves of crystallization in the CuTi glassy tapes ${ }^{26}$. In the present work, we report the existence of selfpropagating crystallization waves in Fe-based amorphous alloys (Fe-B, Fe-Si-B), and present some results on the wave-like crystallization of $\mathrm{Cu}$-Ti metallic glass.

We have studied four compositions of MG tapes produced by melt spinning and are listed in Table 1 (see Supplementary Materials for methods of production and research). 
Table 1. Features of the soft explosive crystallization process.

\begin{tabular}{|c|c|c|c|c|c|}
\hline \multirow[t]{2}{*}{ Composition } & \multicolumn{3}{|c|}{ Infrared Camera measurements } & \multicolumn{2}{|c|}{ DSC measurements } \\
\hline & $\begin{array}{c}\text { Pre- } \\
\text { heating } \\
\text { tempe- } \\
\text { rature } \\
\mathrm{T}_{0}, \mathrm{~K}\end{array}$ & $\begin{array}{l}\text { Max } \\
\text { tempe- } \\
\text { rature } \\
\mathrm{T}_{\text {max }}, \mathrm{K}\end{array}$ & $\begin{array}{c}\text { Propagating } \\
\text { velocity } \\
\mathrm{U}, \mathrm{cm} / \mathrm{s}\end{array}$ & $\begin{array}{l}\text { Heat release } \\
\qquad \mathrm{Q}, \mathrm{J} / \mathrm{g}\end{array}$ & $\begin{array}{c}\text { Energy of Activation } \\
\qquad \mathrm{E}, \mathrm{kJ} / \mathrm{mol} \\
\text { (by Kissinger } \\
\text { method) }\end{array}$ \\
\hline $\mathrm{Fe}_{84} \mathrm{~B}_{16}$ & 580 & 700 & $7.00 \pm 0.04$ & $190 \pm 22$ & $250 \pm 5$ \\
\hline $\mathrm{Fe}_{85} \mathrm{~B}_{15}$ & 570 & 720 & $4.95 \pm 0.02$ & $\begin{array}{c}122 \pm 13 \\
\text { (sum of two } \\
\text { stages) }\end{array}$ & $\begin{array}{c}217 \pm 7 \text { (first stage) } \\
252 \pm 15 \text { (second } \\
\text { stage) }\end{array}$ \\
\hline $\mathrm{Fe}_{76} \mathrm{Si}_{13} \mathrm{~B}_{11}$ & 640 & 740 & $1.26 \pm 0.01$ & - & - \\
\hline $\mathrm{Cu}_{50} \mathrm{Ti}_{50}$ & 500 & 640 & $1.26 \pm 0.01$ & $144 \pm 7$ & $251 \pm 30$ \\
\hline
\end{tabular}

Unlike deposited amorphous films, the MGs do not exhibit explosive crystallization (EC) at room temperature. For this reason, the tapes were pre-heated up to $500-640 \mathrm{~K}$ by passing an electric current (DC) through the tape in Ar flow. The preheating process to $\mathrm{T}_{0}$ was accomplished with heating rate $>200 \mathrm{~K} / \mathrm{min}$ and thus its duration was less than $1 \mathrm{~min}$. Immediately $(\sim 3 \mathrm{~s})$ after the uniform preheating of the tape, an additional short heat pulse was applied locally at one end of the tape to initiate the amorphous-crystalline transition. Values of the pre-heating temperature $\mathrm{T}_{0}$ were chosen well below the crystallization onset temperature $T_{x}$, which was found from the separate DSC measurements and appeared to be in the range $690-720 \mathrm{~K}$ for the Fe-B system and $680 \mathrm{~K}$ for $\mathrm{Cu}$-Ti system. The lowest possible values of $\mathrm{T}_{0}$ and short pre-heating time prevented partial crystallization (devitrification) of the samples during pre-heating stage. The EC wave, which is visible in infrared radiation, self-propagates along the tape (fig. 1 and multimedia view). 


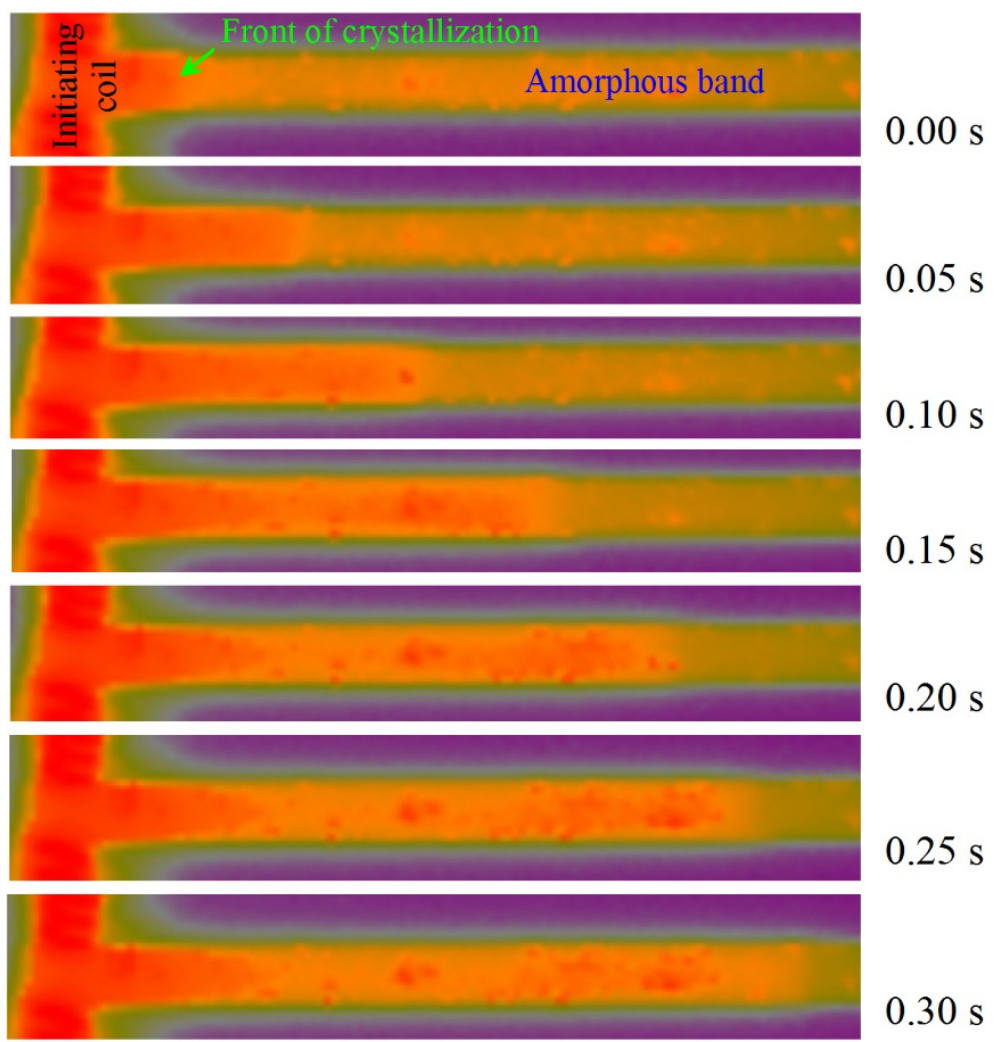

$\longmapsto 2 \mathrm{~mm}$

Figure 1. Infrared images of the propagating crystallization wave in $\mathrm{Fe}_{84} \mathrm{~B}_{16}$ glassy metallic tape. (Multimedia view).

Instant temperature distributions along the direction of wave propagation reveal that, with the existence of the wave front, the temperature drops 100-150 K (fig. 2(a)). The front propagates from left to right (the arrows depict the propagation direction). It should be noted that the temperature remains approximately constant behind the front. Therefore, heat flux from the initiating wire does not affect the front propagation. While the samples do not glow, the front propagating was also observed in the visible light spectrum due to variations of the surface reflectivity in amorphous and crystalline phases. 

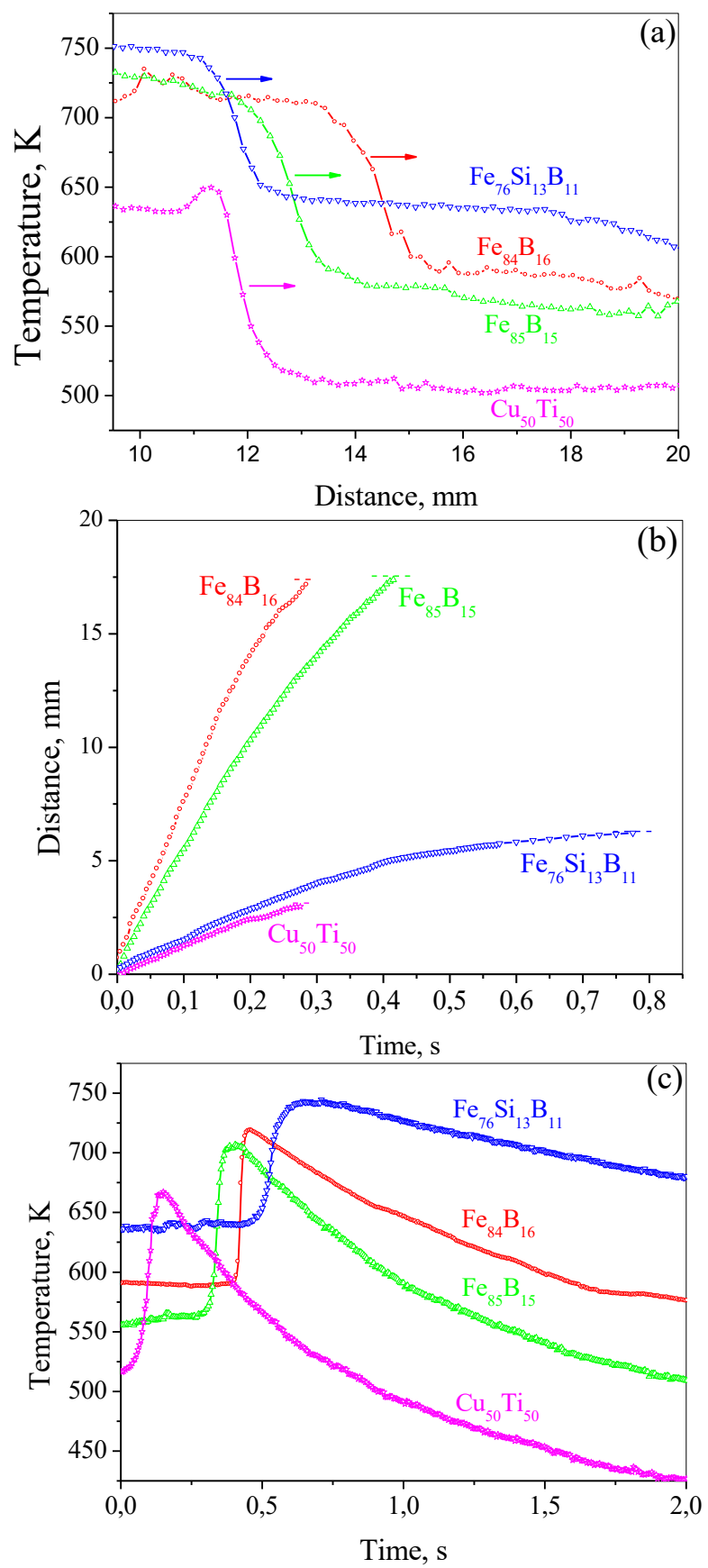

Figure 2. Characteristics of the crystallization wave: (a) temperature distribution along the tape (arrows depict propagation direction); (b) position of the wave front versus time; (c) temperaturetime history measured in one spot $(\sim 0.16-0.18 \mathrm{~mm})$ in the middle of each sample.

The front position time dependence was well fit by a linear function in the middle of the tapes (fig. 2(b)), where the influence of the initiating hot wire from one end and cold steel clip (electrode) from another end are negligible. The macroscopic propagating velocity at this region 
is essentially constant and in the range $1-7 \mathrm{~cm} \mathrm{~s}^{-1}$ (Table 1). When the crystallization front approaches the cold electrode, it typically slows down and propagation becomes auto-oscillating. It is worth noting that the oscillations are more developed in the $\mathrm{Cu}_{50} \mathrm{Ti}_{50}$ and $\mathrm{Fe}_{76} \mathrm{Si}_{13} \mathrm{~B}_{11}$ tapes, while the $\mathrm{Fe}_{84} \mathrm{~B}_{16}$ and $\mathrm{Fe}_{85} \mathrm{~B}_{15}$ tapes exhibit a steady state propagation mode, almost until the end of the tape. Analysis of the temperature-time profiles, measured within the small surface areas in the middle of the samples (fig. 2(c)), shows that maximum self-heating rate in the amorphouscrystalline transition front is $\sim 4300 \mathrm{~K} \mathrm{~s}^{-1}$ and was observed for $\mathrm{Fe}_{84} \mathrm{~B}_{16}$, while $\mathrm{Fe}_{76} \mathrm{Si}_{13} \mathrm{~B}_{11}$ has the minimum self-heating rate of $\sim 1400 \mathrm{~K} \mathrm{~s}^{-1}$. A comparison of the self-heating rates and propagating velocity with those measured for classical EC in electrolytically deposited $\mathrm{Sb}\left(\sim 28000 \mathrm{~K} \mathrm{~s}^{-1}\right.$ heating rate, $>30 \mathrm{~cm} \mathrm{~s}^{-1}$ propagating velocity $)^{27}$ shows that EC in metallic glasses has much "softer" characteristics. In addition, the MGs have much less sensitivity to external stimuli. In our experiments, mechanical impact, scratching, or local heating at room temperature did not initiate the self-propagating crystallization wave. Only the local thermal impulse in the pre-heated sample or uniform heating above $620 \mathrm{~K}$ was found as proper methods for EC initiating ${ }^{26}$. These differences allow us to distinguish between classical EC in deposited films and the soft EC in metallic glasses produced by fast melt quenching. Based on the comparison of the propagating parameters in different systems, we may suggest that EC-waves become weaker and slower with increasing number of elements in the system. Pure elements, such as explosive Sb, exhibit violent EC; binary systems, Fe-B or $\mathrm{Cu}-\mathrm{Ti}$, demonstrate 'softer' self-propagating transformation; ternary system FeSi-B possesses the weakest EC wave. This trend relates, probably, to increasing the glass forming ability and stability of metallic glasses with increasing complexity of their composition. For example, it was shown that adding of Si into the binary Fe-B alloy expands concentration region of amorphous phase ${ }^{28}$. In addition, increasing number of elements may retard crystallization, since long-range diffusion becomes critical for formation of primary ordered clusters ${ }^{29}$. Further research is required to determine the mechanism of EC in the multicomponent bulk metallic glasses. 
According to X-ray diffraction of the tapes before and after passing the EC wave, the Fe$\mathrm{B}$ amorphous alloys crystallized into $\alpha$-Fe and tetragonal $\gamma$ - $\mathrm{Fe}_{3} \mathrm{~B}$ phases and the $\mathrm{Cu}_{50} \mathrm{Ti}_{50}$ metallic glass transformed into a single intermetallic phase of polycrystalline tetragonal CuTi. The differential scanning calorimetry (DSC) results of the thermal effects and activation energies (Table 1) are consistent with those published earlier, e.g., $164-197 \mathrm{~kJ} \mathrm{~mol}^{-1}$ for Fe-B ${ }^{30}$ and $207 \pm 33$ $\mathrm{kJ} \mathrm{mol}^{-1}$ for $\mathrm{Cu}_{50} \mathrm{Ti}_{50}{ }^{31}$. The composition of $\mathrm{Fe}_{85} \mathrm{~B}_{15}$ has two exothermal peaks in the DSC curve that probably relate to the primary crystallization of $\alpha-\mathrm{Fe}$, followed by the crystallization of eutectic $\alpha-\mathrm{Fe}+\mathrm{Fe}_{3} \mathrm{~B} . \mathrm{Fe}_{84} \mathrm{~B}_{16}$, which is closer to eutectic point ( 83 at.\% Fe, 17 at.\% B), has one exothermal peak. Transmission electron microscopy (TEM) shows that the initial foils have a homogeneous microstructure (fig. 3, TEM BF, left column) that transforms into sub-micrometer polycrystalline material after passing the EC wave (fig. 3, TEM BF, right column). The atomic structure evolution, from practically stochastic dispositions of atoms to a long-distance ordered crystal lattice, have been observed by means of high-resolution TEM (fig. 3, HRTEM). These results were confirmed with selected area microdiffraction of electrons (fig.3, SAD). 


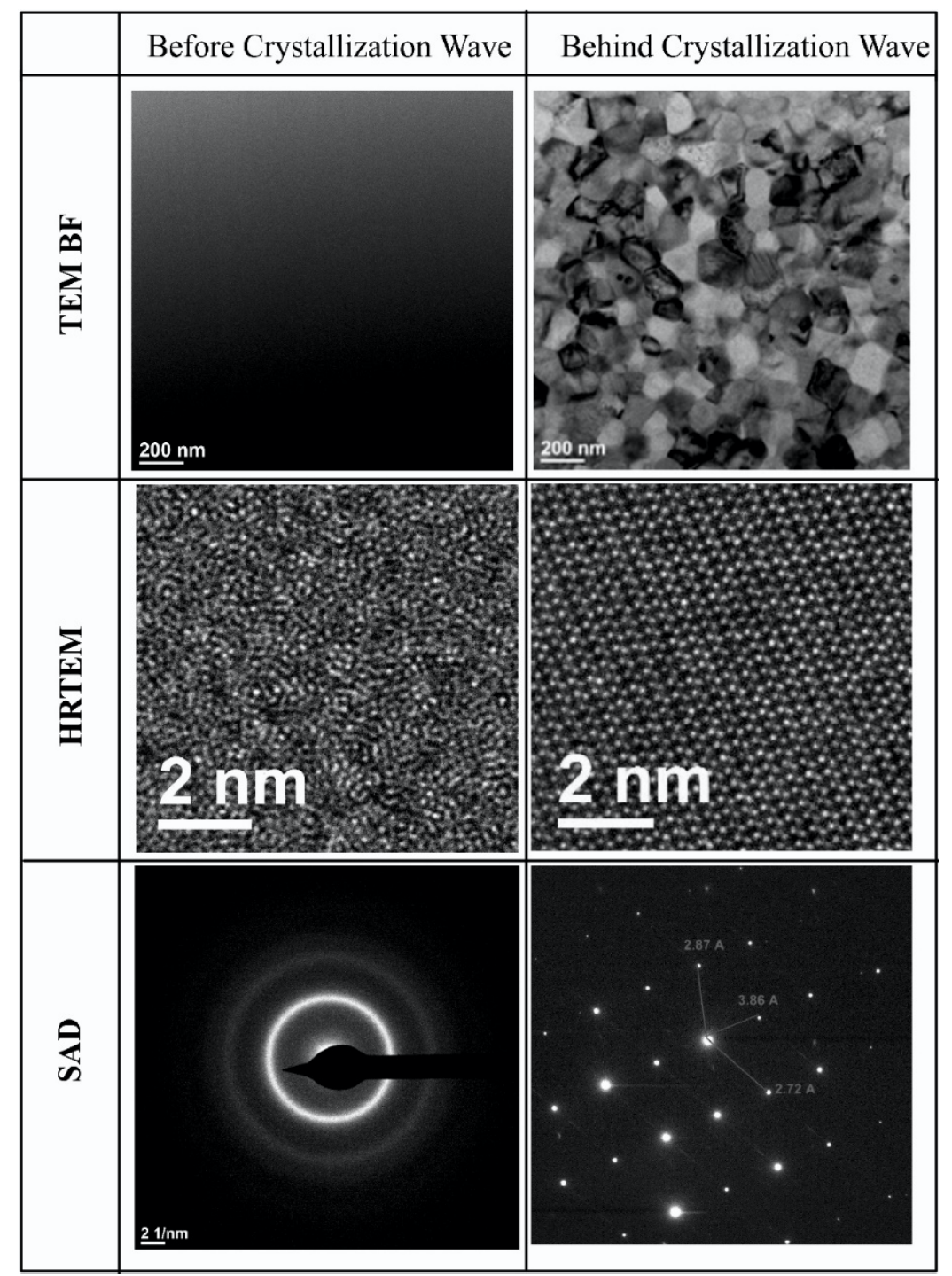

Figure 3. Structure transformations caused by the crystallization wave in the $\mathrm{Fe}_{84} \mathrm{~B}_{16}$ metal glass.

Thus, the structural transformations induced by the self-propagating waves are similar to those that occur in DSC or annealing experiments $\mathrm{s}^{30-32}$.

In order to validate the possibility of EC in metallic glasses at the atomic scale, a molecular dynamics simulation (MDS) of this process in initially amorphous $\mathrm{Cu}_{50} \mathrm{Ti}_{50}$ alloy has been accomplished (see Methods). The $\mathrm{Cu}_{50} \mathrm{Ti}_{50}$ composition was selected for MDS because it undergoes polymorphous transformation, i.e., the amorphous alloy transforms into one crystalline phase of the same composition. This make the MDS procedure easier, and the patterns obtained more obvious. The Fe-based compositions undergo eutectic or two-stage (primary \& secondary) crystallization, when two or more crystalline phases form, including metastable intermediate 
phases. For this reason, MDS of self-propagating waves is a matter of nearest future work. A rectangular, amorphous block $(7760 \times 123 \times 31$ angstroms $)$ composed of $2000400 \mathrm{Cu}$ and $\mathrm{Ti}$ atoms in 50:50 ratio was prepared by virtual rapid melt quenching (see supplementary files with Methods). After quenching, the temperature was $500 \mathrm{~K}$ and the amorphous structure remained steady at these conditions. When a local heat pulse $(650 \mathrm{~K})$ was applied to one end of the block, a self-propagating amorphous-to-crystalline transition wave appeared in the model sample (fig. 4, supplementary video file 2). The temperature rose up to $\sim 630 \mathrm{~K}$ in that wave (fig. $4(\mathrm{a})$ ), which correlates excellently with experimental results (fig. 2). The atomic ordering shows a crystal lattice close to the tetragonal $\mathrm{CuTi}$ structure, however, $\mathrm{Cu}$ and $\mathrm{Ti}$ atoms were randomly distributed in the lattice sites (fig. 4(b)). Thus, according to the molecular dynamic simulation, a crystalline intermetallic phase with disordered atom positions appears behind the EC wave front. The propagation velocity of the simulated virtual waves is about $20-40 \mathrm{~m} \mathrm{~s}^{-1}$, which is considerably higher than experimentally observed. This discrepancy probably relates to very different spatial and temporal scales in the experimental and modelling research of EC. Experimentally, we observe propagation of the EC wave at distances of up to several $\mathrm{cm}$, while the model considers the propagation at distance of $\sim 0.7 \mu \mathrm{m}$. Since the crystalline product consists of polycrystalline grains with size $\sim 1 \mu \mathrm{m}$ (e.g., see fig.3 TEM BF; polycrystalline structure was also observed for explosively crystallized CuTi), the MDS evidently shows crystallization inside one grain. We can assume here that the real EC wave propagates faster inside the crystalline grain and stays at the grain boundaries, which decreases the average macroscopic propagation velocity. A similar effect of rapid propagation of short distances followed by delays at the boundaries between structural elements was also observed for propagation of the crystallization wave along a chain of amorphous Ni particles ${ }^{33}$, and periodic "leading wave crystallization" in amorphous Si films ${ }^{24}$. Good correlations between MDS and experimental results not only give more evidence for the existence of EC waves in the metallic glasses, but also provide a tool for understanding the intimate 
features of the process that cannot be currently investigated by experimental methods, for example movements of individual atoms in the crystallization wave (fig. 4(b) and multimedia view).

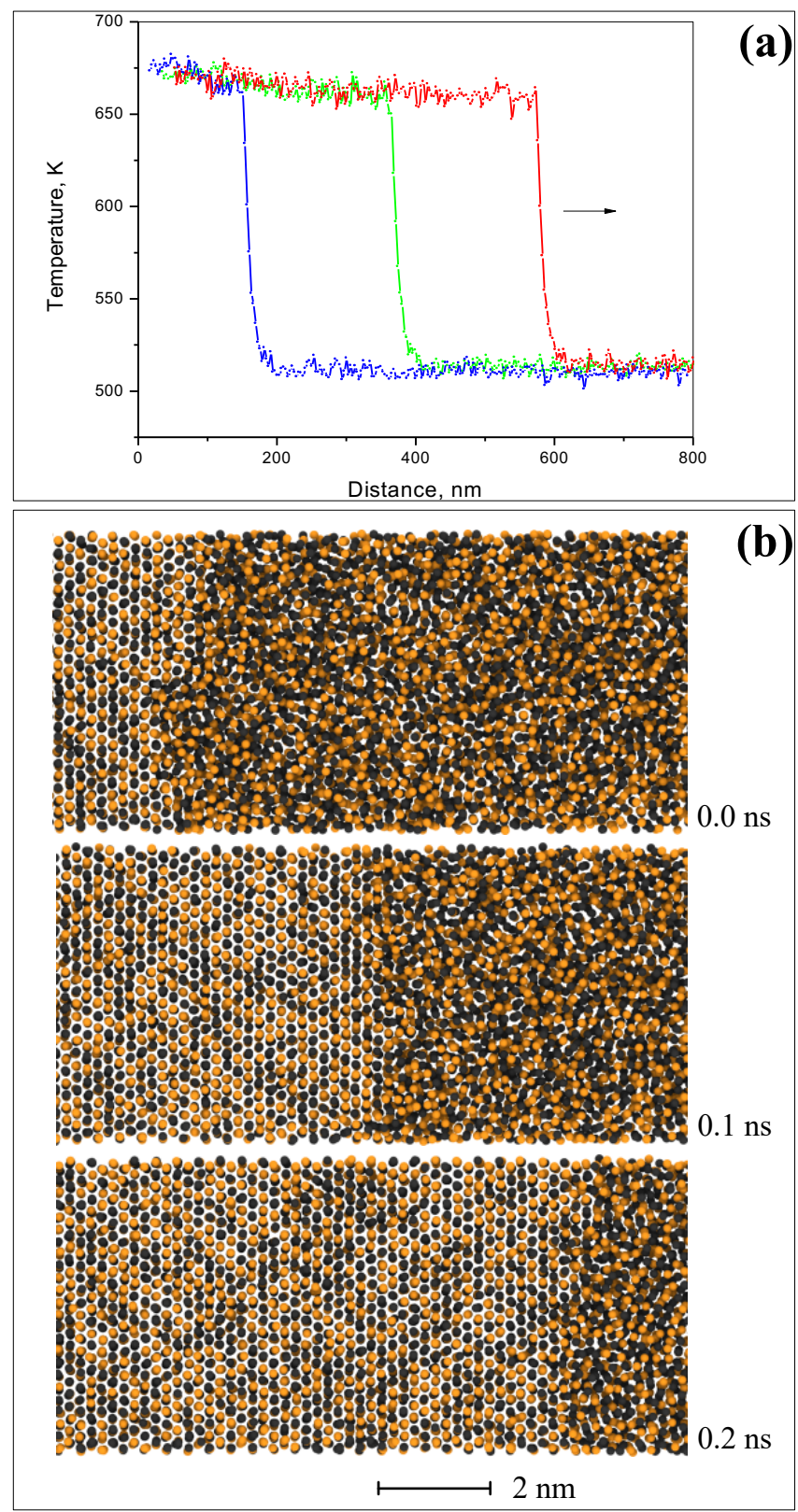

Figure 4. Molecular dynamic simulation of the self-propagating crystallization wave in the $\mathrm{Cu}_{50} \mathrm{Ti}_{50}$ metallic glass. Temperature profiles of the wave (a) and selected cross-sections of the virtual sample (b). The golden balls are $\mathrm{Cu}$ atoms and the black balls are Ti. (Multimedia view). 
The practical meaning of the soft explosive crystallization phenomena is to be elucidated in the future. We should note that EC in the deposited semiconductor films is used for converting amorphous $\mathrm{Si}, \mathrm{Ge}$, etc. into polycrystalline materials required for solar cells ${ }^{21-24}$. The SEC can play a similar role for metallic glasses. This conversion may be the most significant for bulk metal glasses, because self-propagating EC waves induce a soft, pre-determined self-heating in all points of the sample independently of the spatial location or depth within the sample. In such a way, SEC can create uniform (or lamellar in case of oscillating propagation ${ }^{26}$ ) polycrystalline microstructures favorable for mechanical, magnetic, and other properties of materials.

\section{SUPPLEMENTARY MATERIALS}

See supplementary materials for detailed methods description, IR video of the waves (multimedia files "Figure_1.mov" and "supplemental_video_CuTi.wmv") and Molecular Dynamic Simulation of the wave (multimedia file "Figure_4.mov").

\section{ACKNOWLEDGEMENTS}

This work is supported by Russian Science Foundation (project no. 16-13-10431); using of the high-speed IR camera was possible due to financial support of the Ministry of Education and Science of the Russian Federation in the framework of Increase Competitiveness Program of NUST «MISiS» (№ K2-2016-002), implemented by a governmental decree dated 16th of March 2013, N 211.

\section{References}

1. Gore, G., On a peculiar phenomenon in the electro-deposition of antimony. The London, Edinburg, and Dublin philosophical magazine and journal of science 9, 73-74 (1855).

2. Prins, J.A. Diffraction of electrons in amorphous and in crystalline antimony. Nature 131, 760-761 (1933). 
3. Duwez, P., Willens, R.H. \& Klement Jr., W. Continuous series of metastable solid solutions in silver-copper alloys. J. Appl. Phys. 31, 1136-1137 (1960).

4. Klement Jr., W., Willens, R.H. \& Duwez, P. Non-crystalline structure in solidified goldsilicon alloys. Nature 187, 869-870 (1960).

5. Weber, A.W. \& Bakker, H. Amorphization by ball milling. A review. Physica B 153, 93135 (1988).

6. Politis, C. Bulk Amorphous and nanostructured materials by high energy ball milling. Int. J. of Modern Physics B 22, 2905-2913 (2008).

7. Reer, A.L. Metallic Glasses. Science 267, 1947-1953 (1995).

8. Wang, W.H. Metallic Glasses. Family traits. Nature Materials 11, 275-276 (2012).

9. Johnson, W.L. \& Plummer, J. Is metallic glass poised to come of age? Nature Materials 14, 553-555 (2015).

10. Hasegawa, R. Applications of amorphous magnetic alloys. Materials Science and Engineering: A 375-377, 90-97 (2004).

11. Si, J., Mei, J., Wang, R., Chen, X. \& Hui, X. Fe-B-Si-Zr bulk metallic glasses with ultrahigh compressive strength and excellent soft magnetic properties. Materials Letters 181, 282-284 (2016).

12. Ashby, M.F. \& Greer, A.L. Metallic glasses as structural materials. Scripta Materialia 54, 321-325 (2006).

13. Schuh, C.A., Hufnagel, T.C., \& Ramamurty, U. Mechanical behavior of amorphous alloys. Acta Materialia 55, 4067-4109 (2007).

14. Ma, E. Tuning order in disorder. Nature Materials 14, 547-552 (2015).

15. Vauth, S., \& Mayr, S.G. Atomic dynamics in molecular dynamics simulation of glassy CuTi thin films. Appl. Phys. Lett. 86, 061913(1-3) (2005).

16. Yavari, A.R. A new order for metallic glasses. Nature 439, 405-406 (2006). 
17. Johnson, W.L. Bulk metallic glasses - a new engineering material. Current Opinion in Solid State \& Materials Science 1, 383-386 (1996).

18. Ding, S., Liu, Y., Li, Y., Liu, Z., Sohn, S., Walker, F.J. \& Schroers J. Combinatorial development of bulk metallic glasses. Nature materials 13, 494-500 (2014).

19. Zhong, L., Wang, J., Sheng, H., Zhang, Z. \& Mao, S.X. Formation of monoatomic metallic glasses through ultrafast liquid quenching. Nature 512, 177-180 (2014).

20. Götzberger, A., Über die kristallisation aufgedampfter antimonschichten. Zeitschrift für Physik 142, 182-200 (1955) (in German).

21. Leamy, H.J., Brown, W.L., Celler, G.K., Foti, G. \& Gilmer, G.H. Explosive crystallization of amorphous germanium. Appl. Phys. Lett. 38(3), 137-139 (1981).

22. Aleksandrov, L.N. \& Edelman, F.L. Shock crystallization of films. Phys. Stat. Sol. (a) 76, 409-427 (1983).

23. Ohdaira, K., Fujiwara, T., Endo, Y., Nishizaki, S. \& Matsumura, H. Explosive crystallization of amorphous silicon films by flash lamp annealing. J. Appl. Phys. 106(4), 044907(1-8) (2009).

24. Hayashi, S., Fujita, Y., Kamikura, T., Sakaike, K., Akazawa, M., Ikeda, M. \& Higashi, S. Leading Wave Crystallization Induced by Micro-Thermal-Plasma-Jet Irradiation of Amorphous Silicon Films. Japanese Journal of Applied Physics 52, 05EE02(1-6) (2013).

25. Z. Altounian, C. A. Volkert, and J. O. Strom-Olsen, Crystallization characteristics of FeZr metallic glasses from Fe43Zr57 to Fe20Zr80. Journal of Applied Physics 57, 17771782 (1985); doi: 10.1063/1.334455.

26. Rogachev, A.S., Vadchenko, S.G., Shchukin, A.S., Kovaleva, I.D. \& Aronin, A.S. Selfpropagating crystallization waves in the TiCu amorphous alloy. JETP Letters 104, 726729 (2016). 
27. Rogachev, A.S., Vadchenko, S.G. \& Shchukin, A.S. SHS reaction and explosive crystallization in thin films: resemblance and distinction. Int. J. Self-Propag. High-Temp. Synth. 26, 44-48 (2017).

28. Shao, G., Lu, B., Liu, Y.Q. \& Tsakiropoulos P. Glass forming ability of multi-component metallic systems. Intermetallics 13, 409-414 (2005).

29. Chen, N., Martin, L., Luzguine-Luzgin, D.V. \& Inoue A. Role of alloying additions in glass formation and properties of bulk metallic glasses. Materials 3, 5320-5339 (2010).

30. Abrosimova, G.E. \& Aronin, A.S. Reversible structural changes on heat treatment of amorphous Fe-B alloys. Int. J. of Rapid Solidification 6, 29-40 (1991).

31. Shanker Rao, T.L., Lad, K.N. \& Pratap, A. Study of non-isothermal crystallization of amorphous $\mathrm{Cu}_{50} \mathrm{Ti}_{50}$ alloy. Journal of Thermal Analysis and Calorimetry 78, 769-774 (2004).

32. Kovalev, D.Yu., Vadchenko, S.G., Rogachev, A.S., Aronin, A.S. \& Alymov, M.I. Timeresolved X-ray diffraction study of the transition of an amorphous $\mathrm{TiCu}$ alloy to the crystalline state. Doklady Physics 62, 111-114 (2017).

33. Manukyan, K.V., Shuck, C.E., Cherukara, M.J., Rouvimov, S., Kovalev, D.Y., Strachan, A. \& Mukasyan, A.S. Exothermic Self-Sustained Waves with Amorphous Nickel. J. Phys. Chem. C 120, 5827-5838 (2016). 